\title{
无人机航空摄影测量在地形图测绘中的应用
}

\section{Application of UAV Aerial Photogrammetry in Topographic Mapping}

\section{李勇}

\author{
Yong Li
}

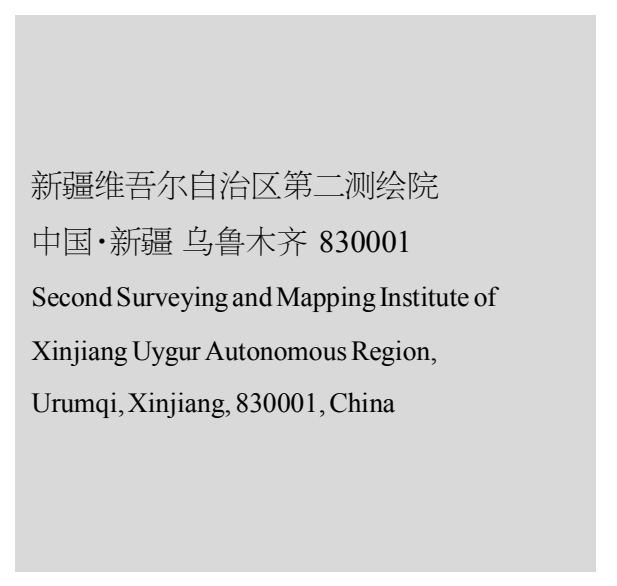

\section{1 引言}

无人机航空摄影测量技术在国家基础测绘工作中运用十 分广泛, 不仅能够弥补传统测绘技术的不足, 还因其范围性、灵 活性、便捷性,在地形图测绘中发挥巨大作用。加强对无人机航 空摄影测量在地形图测绘中应用的研究具有十分现实的意义。

\section{2 无人机航空摄影概述}

无人机航空拍摄主要是通过无人机空中平台, 利用高分 辨率的数码相机、摄像机等,获取视频、图像信息。还可以采用 一些航空摄影拍摄图像信息处理,制作成 3D 产品,包括数字 高程模型、正射影像图、地形图等吕。无人机航摄技术集合了 高空拍摄、遥感、遥控、拍摄测量等, 能够实现有人飞机无法完 成的任务。

正是由于无人机航空摄影测量技术的优势, 在诸多领域 都具有重要运用。而这些优势, 是由于其集中了诸多先进技 术、设备, 与常规航摄系统相比, 无人机航空摄影测量并不需 要在专业机场起降,携带十分便捷, 能快速执行相关的测量工 作, 同时, 可以利用高质量的数码相机传感器、飞行平台、飞行 控制设备,系统集成性较高。

\section{3 无人机航空摄影测量技术在地形图测 绘中的具体运用}

\section{1 像片控制测量}

在无人机航空摄影技术运用中，对像片的控制测量是十 分重要的技术, 具体是将无人机航空拍摄资料, 和 GPS 系统
中导航定位进行融合, 并将无人机航空拍摄中获取的资料对 比, 根据地面测量数据实施有效的换算转换, 以便于获得更加 精确的地形、地貌特征。对于一些特殊地形区域,利用对像片 控制测量技术, 能够实现对数据的实时传输、保存 ${ }^{[2]}$ 。合理布 置像片控制点是像片控制技术的核心，必须合理设置像片控 制点以外的控制点, 将其设置在较为明显地点, 以便于能够获 得精准、理想的数据。

\section{2 空中三角测量}

利用航空摄影测量技术, 需要根据航线重叠度要求整理 航片, 不仅需要满足 $60 \%$ 重叠度, 将多余航片剔除后, 减少空 三加密、测图影像数量以及正射影像图制作, 同时需要增加航 线基高比,以便于保证成图高程精读。对相机检校文件是否一 致、完整进行检查，同时注意相机焦距、地面分辨率。首先对四 周关键位置进行量测, 包括目标清晰的控制点, 然后在概略平 差之后, 对控制点进行进一步控制, 直到对所有控制点量测工 作完成。采用渐进式模式进行控制点量测, 先对没有疑问控制 点进行量测, 最后对有疑问控制点进行量测。之后对空三结果 精度检验。将加密成果、外业成果实施有效对比,并将加密成 果导入立体测图模块中, 将内外业实测成果加以对比检查。完 成上述工作之后, 输出加密结果, 形成相对完整的影像外方位 元素成果。

\section{3 立体采编测量数据}

通过无人机航空摄影拍摄技术获取有关数据后，利用业 内立体信息,将测量区域地形数据进行有效采编,并做好数据

(下转第 55 页) 
表 1 倾斜相机参数

\begin{tabular}{c|c}
\hline 指标 & 参数 \\
\hline 飞行时间 $/ \mathrm{min}$ & 45 \\
\hline 起飞重量 $/ \mathrm{kg}$ & 10 \\
\hline 像素 & 120000000 \\
\hline 像元 $/ \mu \mathrm{m}$ & 3.92 \\
\hline 像幅 & $4000 \times 6000$ \\
\hline 焦距 $/ \mathrm{mm}$ & 35 \\
\hline
\end{tabular}

表 2 航线设计参数

\begin{tabular}{c|c}
\hline 项目 & 指标 \\
\hline 航线间隔 $/ \mathrm{m}$ & 30 \\
\hline 航对航高 $/ \mathrm{m}$ & 90 \\
\hline 地面分辨率 $/ \mathrm{m}$ & 0.02 \\
\hline 基线 $/ \mathrm{m}$ & 13 \\
\hline 旁向重叠 $/ \%$ & 60 \\
\hline 航向重叠 $/ \%$ & 80 \\
\hline
\end{tabular}

配高程和平面坐标; 第三,密集匹配,对多张影像上的同一个 特征点进行匹配, 并对影像之间的空间变换模型进行计算。

(2)三维测图。在农村不动产登记工作中, 最基本的要求是 对农村房屋进行逐栋测量, 即通过三维测图系统（EPS 3D Survey) 对带有实际地理位置的三维模型数据进行加载, 并结 合二三维交互采编采集一体化，对农村地物直接进行测图采 集, 不用进行房檐改正, 从而生成不动产三维模型立体测图。

(3)三维模型精度分析。测图工作在完成以后,想要对所建

\section{（上接第 53 页）}

管理工作。这一环节中, 必须对控制物体线节点、地形结构数 据进行精确的控制, 对无人机航空摄影获取的数据进行严格 审查、确认, 否则就会对立体采编精准性造成影响。

\section{4 数字地形图测绘工作}

配合全数字摄影测量工作站, 能够实现对地形图绘制的 立体数字测图, 利用无人机航空数字影像建立立体模型, 对相 关数据进行采集并形成图形文件。利用采用空三导入模式,检 查导入成果, 具体检查工作中, 是将外业检查点与空三加密使 用像片控制测量点导人测图工程中, 利用立体映射控制点进 行精读检查。在立体模型下对地形地貌、地物进行量测, 坚持 内业定位、外业定性的基本原则, 根据外业调绘内容, 实现精 确的测绘。在测图过程中,必须注意地物与地貌、地貌与地貌 之间的关系, 对于高层建筑物、树冠、阴影遮盖的地物内业可 以不测绘, 但需要利用外业进行补测。电杆等内业无法准确定 位的地物要素, 也需要利用外业进行实地补测。在数据量测完 后, 必须对地物采集精读、要素丢漏情况进行详细检查, 并进 行有效的改正。

\section{5 盲点测量、外业补测}

众所周知，现在任何先进的测绘工具都无法将全部地形
模型的精度进行验证, 就需要对数字线画图的要素精度进行 检验。即选择 16 个比较明显的地物点来当作检测点进行检测 (见表 3)。通过检测发现, 平面误差为 $0.03 \mathrm{~m}$, 高程中的误差为 $0.04 \mathrm{~m}$, 满足农村不动产登记测量的要求。

表 3 检测点误差统计

\begin{tabular}{c|c|c||c|c|c}
\hline 点号 & 平面误差 $/ \mathrm{m}$ & 高程误差 $/ \mathrm{m}$ & 点号 & 平面误差 $/ \mathrm{m}$ & 高程误差 $/ \mathrm{m}$ \\
\hline 1 & 0.01 & 0.01 & 9 & 0.06 & 0.06 \\
\hline 2 & 0.03 & 0.08 & 10 & 0.05 & 0.07 \\
\hline 3 & 0.05 & 0.09 & 11 & 0.03 & 0.03 \\
\hline 4 & 0.01 & 0.02 & 12 & 0.03 & 0.06 \\
\hline 5 & 0.04 & 0.06 & 13 & 0.03 & 0.02 \\
\hline 6 & 0.01 & 0.05 & 14 & 0.01 & 0.00 \\
\hline 7 & 0.01 & 0.08 & 15 & 0.00 & 0.03 \\
\hline 8 & 0.00 & 0.03 & 16 & 0.01 & 0.00 \\
\hline
\end{tabular}

\section{4 结语}

总的来说, 倾斜摄影测量技术作为一项新技术, 可对地物 进行全方位、多角度立体测量, 以此使测绘工作者的工作效率 得到提高的同时, 还能缩短工作时间。还有通过倾斜摄影测量 技术可对房屋的每层信息进行真实反映，直观性比较强的同 时,也能很好地反映隐蔽地区。

\section{参考文献}

[1]杨宏健,郑三君.无人机倾斜摄在农村不动产测量中的应用 $[\mathrm{J}]$. 测绘技术装备, 2017(11):81-83.

区域进行测量, 无人机航空摄影也是如此。对于测量过程中存 在的盲点,需要采用人工补测模式,对地形结构、隐蔽区域进 行测量。外业补测过程中, 必须对对比分析工作加以重视, 将 实际测量数据和无人机航摄获得数据进行对比, 保证测绘数 据的可靠准确。如果两者具有较大偏差,必须对人工测量、无 人机测量哪一个存在误差进行分析, 并进行及时修正处理, 保 证整个测绘结果精准。

\section{4 结语}

通过上述分析可知,在中国社会经济快速发展过程中,越 来越多基础设施工程投入建设中，对于地形数据要求也逐渐 提升, 传统测绘技术无法满足相关要求。无人机航空摄影测量 技术是先进的测量技术, 具有实时性、全天时、全天候的优势， 在地形图测绘中具有重要的作用。

\section{参考文献}

[1]王超.无人机航空摄影测量在地形图测绘中的应用探讨[J].城 市地理.2017,14(8):21-22.

[2]陈键锋. 无人机航空摄影测量在地形图测绘中的应用探讨 [J]. 内蒙古煤炭经济.2017,25(8):99-102. 